ESTUDAM Bilișim Dergisi

Cilt 3, Say1 1, 1-5, 2022

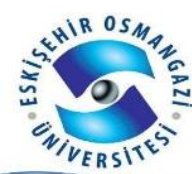

ESTÜDAM
Journal of ESTUDAM Information

Volume 3, Issue 1, 1-5, 2022

DOI: 10.53608/estudambilisim.1015402

(Geliş Tarihi / Received Date: 27.10.2021, Kabul Tarihi/ Accepted Date: 15.12.2021)

\title{
Akıllı Konut Uygulaması
}

Muammer AKÇAY*1, Mehmet Canbaz ${ }^{2}$, Muhammet Ömer Diş ${ }^{3}$

${ }^{1}$ Kütahya Dumlupınar Üniversitesi, Mühendislik Fakültesi, Bilgisayar Mühendisliği Bölümü, Kütahya, ORCID No: https://orcid.org/0000-0003-0244-1275

${ }^{2}$ Eskişehir Osmangazi Üniversitesi, Mühendislik Mimarlık Fakültesi, İnşaat Mühendisliği Bölümü, Eskişehir, ORCID No: https://orcid.org/0000-0002-0175-6155

${ }^{3}$ Kahramanmaraş Sütçü İmam Üniversitesi, Mühendislik Mimarlık Fakültesi, İnşaat Mühendisliği Bölümü, Kahramanmaraş, ORCID No: 0000-0002-3347-5112

Anahtar Kelimeler: ak1llı binalar, iklimlendirme, su tasarrufu, güvenlik sistemleri, aydinlatma sistemleri, bilgi teknolojileri
Özet: Otomasyon sistemleri günümüzde sadece endüstriyel uygulamalarla kısıtlanmayıp, akıllı binalarda da kullanılmaktadır. Akıllı binalar bilim ve teknolojinin ilerlemesiyle en önemli otomasyon konularından biri olmuştur. Binalarda iklimlendirmeye (1sıtma ve soğutma), aydınlatmaya ve su tüketimine büyük enerji kullanılır. Dünyada giderek artan çevre sorunları ve tükenen doğal kaynaklar dolayısı ile enerji tüketimine dikkat edilmesi gereken konulardandır. Dünyadaki enerjinin \% 30-40'1 binalarda kullanılmaktadır. Özellikle tükenmekte olan enerjiyi yenilenebilir hale dönüştürmek ve minimum şekilde kullanmak için akıllı binalar büyük bir firsat sunmaktadır. Sürdürülebilir kentler kavramı otomasyon sistemleri ile iç içe geçen bir konu olmuştur. Sürdürülebilirlik çerçevesinde akıllı bina uygulamaları, mimari tasarım parametreleriyle, mekanik, elektrik, elektronik, bilgisayar ve bilişim sistemleriyle ilişkilidir. Bina içerisindeki sıcaklığın istenilen düzeyde tutulması insanların konfordan beklentilerini karşılarken, aynı zamanda etkin enerji kullanımını da sağlayan otomasyon uygulamalarının güzel örneklerinden birisidir. Enerji tüketimine yönelik olarak su tüketimi, aydınlatma ve güvenlik uygulamaları da akıllı binalar kapsamında ülkemizde son zamanlarda yer almaktadır. Bu amaçla yapılan çalışmada akıllı ev sisteminin bir modeli oluşturularak mobil ara yüzü ile etkileşim sağlanmıştır.

\section{Smart Housing Application}

\section{Keywords:}

smart buildings, air conditioning, saving on water, security systems, lighting systems, information technologies

\begin{abstract}
Automation systems are not limited to industrial applications today, but smart buildings have become one of the most important automation issues with the advancement of science and technology. A great deal of energy is spent on air conditioning (heating and cooling), lighting and water consumption in buildings. Due to the increasing environmental problems and depleting natural resources in the world, energy consumption is one of the issues to be considered. 30-40\% of the world's energy is used in buildings. In particular, smart buildings offer a great opportunity to transform consuming energy into renewable energy and to use it in a minimum way. The concept of sustainable cities has become a subject that is intertwined with automation systems. In the framework of sustainability, smart building applications are related to architectural design parameters, mechanical, electrical, electronic, computer and information systems. Keeping the temperature in the building at the desired level is one of the good examples of automation applications that provide effective energy use while meeting the expectations of people from comfort. Water consumption, lighting and security applications for energy consumption are also included in the scope of smart buildings in our country recently. These practices support the welfare of individuals and their sensitivity to the environment. It is expected that these practices will continue increasingly within the scope of sustainable urbanism. In this study, a model of the smart home system was created. Interaction is provided with the mobile interface.
\end{abstract}




\section{GİRiş}

Gelişen teknoloji ile birlikte değişen yaşam tarzları insanların konfordan beklentilerini de yükseltmektedir. Yenilikçi otomasyon sistemleri bu beklentilerin karşılanması için binalarda uygulanmaya başlamıştır. Binaların mimari tasarım parametreleriyle yenilenebilir enerji kaynaklarından yararlanması, mekatronik sistemlerle enerji yönetimi, güvenlik sistemleriyle hassas ve güvenilir uygulamalar ve bu sistemlerin tam bir entegrasyon ile verimli şekilde çalışması için binalarda otomasyon sistemleri kurulmuş ve geliştirilmiştir.

Akıllı binaların standart bir tanımlaması olmayıp inşaat endüstrisine dayalı tanımları mevcuttur. Akıllı binalar, ilgili kavram içerisinde sürdürülebilirliğe ek olarak sağlıklı, teknolojiye uyumlu, kullanıcıların ilgilerini ve ihtiyaçlarını karşılayan ayrıca çevresel koşullar ve teknolojik değişiklikler doğrultusunda entegre olabilen bir yapıya sahip olan binalar olarak tanımlanmıştır [1]. Akıllı bina kavramı ilk olarak 1980'lerin başında Amerika Birleşik Devletlerinde kullanılmaya başlanmış olup, Türkiye'deki ilk uygulaması ise 1984 yılındadır [2]. İlk sistemler aktif kontrol mekanizmaları olmayıp yalnızca izlemeye yöneliktir [3]. Günümüzde ise ak1llı bina uygulamaları iletişim, haberleşme ve bilişim teknolojilerindeki ilerlemelere paralel olarak insan müdahalesi olmadan oluşturulan otomasyon sistemleriyle yapılabilmekte ve gelişmektedir [4-6].

Otomasyon sistemleri, insanların barınma ihtiyaçlarına ek olarak değişen yaşam tarzlarını karşılarken, kaynakların verimli kullanımını da desteklemektedir. Enerjinin büyük bir oranı insan ihtiyaçlarını ve beklentilerini karşılamak üzere iklimlendirme, güvenlik, su ve aydınlatma amaçlı olarak binalarda kullanılmaktadır. Binalarda kullanılan enerjinin toplam enerjiye oranı dünyada \%45-50 çıkmaktadır [8]. Bu çalışmada akıllı binalarda, iklimlendirme (Isıtma ve Soğutma), aydınlatma, ev cihazlarının kontrolü ve güvenlik sistemleri dikkate alınmıştır.

\section{AKILLI BİNALARDA TASARRUF}

Gelecek nesiller için en iyi yatırım kuşkusuz tasarruftur. Kalite ve konfordan ödün vermeden tüketilen enerji miktarının en aza indirilmesi enerji verimliliği olarak tanımlanabilir. Enerji yönetimi bina ile ilgili her aşamada olmakla beraber akıllı bina uygulamalarında mimari tasarım parametreleri enerji verimliliği açısından önemli bir yer teşkil etmektedir. Binanın yeri, binanın diğer binalara göre konumu, binanın yönü, iç ve dış cephe kabuğu; çevresel etkenlerden, güneş ve rüzgâr gibi yenilenebilir enerji kaynaklarından yararlanma/korunma olanağını ve dolayısıyla enerji verimliliğini etkileyen önemli tasarım parametreleridir. Panjur sistemleri güneş 1şınlarının eve gelişini otomatik olarak ayarlanmakta, 1 şı denetenimi ve gölgeleme elemanı olarak kullanılmaktadır (Şekil 1).

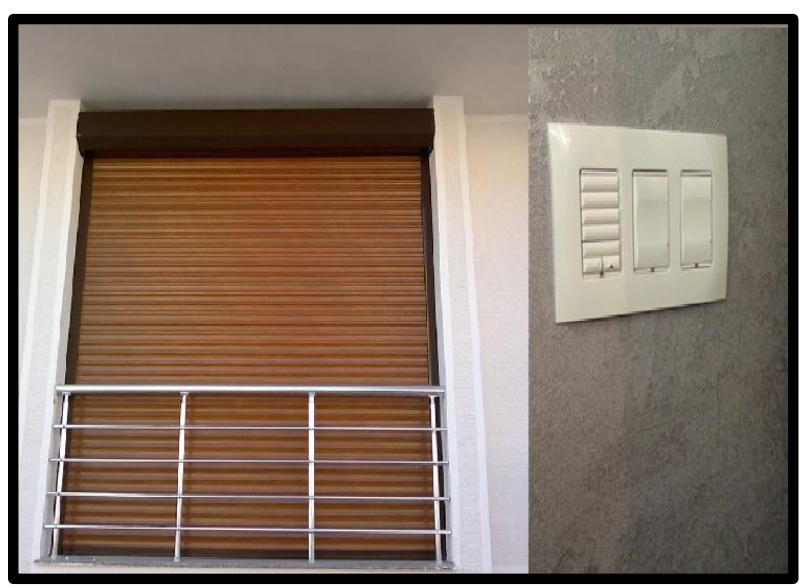

Şekil 1. Pencere panjur sistemleri

Ayrıca gereksiz su tüketimini ve aydınlatma israfını önlemek ve 1sı kayıplarını minimize etmek için tasarlanan akıllı binalar insan hayatını kolaylaştırırken enerji tasarrufu da sağlamaktadır [8]. Toprağa yerleştirilen nem sensörlerinden otomasyon yardımıyla fazla sulamanın önlenmesi, aydınlatmanın zamana göre otomasyonu, güneş enerjileri yardımıyla sıcak su kullanımı akıllı binalarda enerjiyi verimli şekilde kullanıma yönelik örneklerden sadece birkaçıdır. Örneğin evsel atık sularının (gri su) yeniden tuvalet sifonlarında ve bahçe sulamada kullanımı, mutfak ve banyo gibi yerlerde düşük akışlı musluklar ve fotoselli lavabo muslukları hem kullanıcıların lavabo ile teması olmadığından sağlıklı olup hem de daha az su harcamaktadır.

\section{AKILLI BINNALARDA İKLIMMLENDİRME SISTEMLERI (ISITMA VE SOĞUTMA)}

Dört mevsimin yaşandığ 1 fakat coğrafi bölgelerine göre iklimlendirme ihtiyaçlarının farklılaştığı Türkiye'de, soğuk orta ve doğu bölgelerinde isitma sistemleri daha öne çıkarken, sıcak akdeniz ve güneydoğu bölgelerinde soğutma sistemleri, batı bölgelerinde ise havalandırma sistemleri önem kazanmaktadır. Isı ölçüm cihazlarının olmadığ 1 ve merkezi 1sıtma sistemine sahip eski tip binalarda alt katlar daha fazla 1sınırken üst katlarda ısınamama problemleri yaşanabilmektedir. Akıllı binalarda gelişen teknoloji ile birlikte binalar çok daha gelişmiş 1sıtma ve soğutma sistemleriyle donatılmakta enerji tasarrufu ve konfor daha da arttırilabilmektedir.

Akıllı binalarda iklimlendirme sistemleri kaynakların verimli yönetimini ve sürdürülebilirliğini sağlamalıdır. Otomasyon sistemleri bina içerisindeki hava kalitesini ve sıcaklığı termostat kontrolüyle ve dış hava kompanzasyonu ile (dış hava şartlarına göre çalışan cihaz) gerekli taze hava miktarının ve ısının ayarlanmasına olanak vermektedir. Bilgisayar ve telekomünikasyon teknolojilerinin otomasyonlarıyla 1sının istenilen düzeyde tutulması ve uzaktan yönetimi sağlanmaktadır [9]. Bu sistemlerle dışarıdayken binanın sıcaklığını minimum seviyeye indirilerek uzaktan sicaklığı ayarlayabilir, konfordan ödün vermeden enerji tasarrufu yapılabilmektedir. Gece saatlerinde yatak odasının 1sısını ideal seviyeye getirirken, diğer odaların sıcaklığını en az seviyede tutmak mümkündür. Bunların yanı sıra akıllı 
binalarda yine klimalarda tablete bağlanarak soğukluk derecesini ayarlamak mümkündür (Şekil 2).

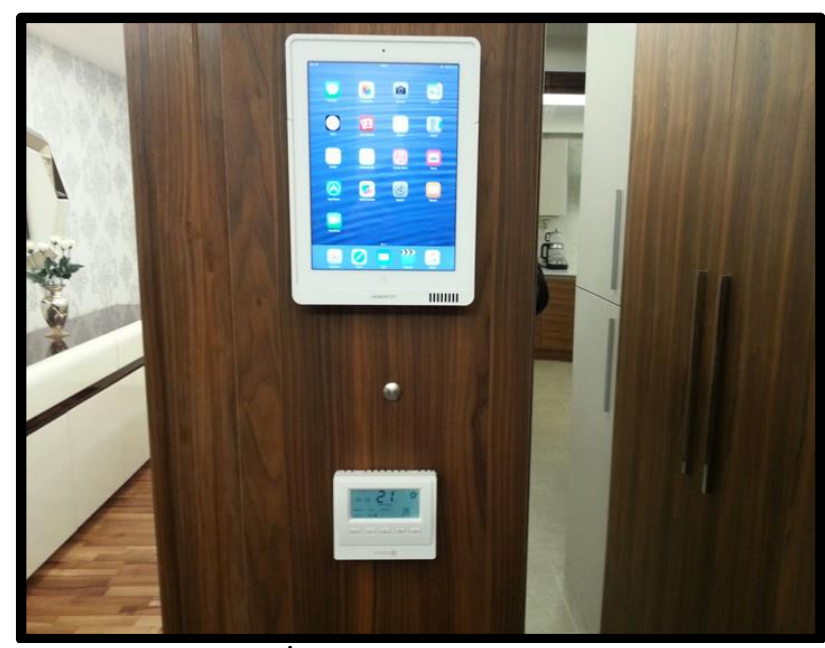

Şekil 2. İklimlendirme otomasyonu

\section{AKILLI BINALARDA EV CIHAZLARININ KONTROL ̈̈}

Teknolojik gelişmeler, artan yaşam standartlarını destekleyecek şekilde kullanılmaktadır. Zamana ve koşullara göre programlanabilen, sensörlere göre tepki veren akıllı binalarda ev cihazlarının kontrolü sistemin sağladığ 1 avantajlardır [10]. Posta geldiğinde algılayıp ev sahibine bilgi veren akıllı posta kutuları, ev sakinlerinin ve yetkili kişilerin anahtarsız girişlerini kolaylaştıran kapılar, harekete duyarlı 1şıklar, zamana göre açılıp kapanabilen perdeler, odaların şeklini ve eşyaların yerini kaydederek temizlik yapabilen süpürgeler, akıllı çamaşır ve bulaşık makineleri, internete bağlı televizyonlar örnek uygulamalar olarak verilebilir.

Otomasyon sistemleri bir dokunuşla insanların konforlarını karşılamanın yanında enerjiyi en akıllı şekilde kullanmaya da olanak sağlamaktadır. Akıllı binalar enerji etkin kullanımında, minimum enerji kullanımı ve tüketilen enerjiden optimum yarar sağlamayı amaçlamaktadır [11]. Aydınlatma bir binadaki en önemli enerji harcamalarından birisidir. Binalarda tüketilen elektrik enerjisinin \%60'1 aydınlatma amaçlıdır [1]. Yenilenebilir güneş enerjiden faydalanıp minimum yapay aydınlatma sağlanırken maksimum dış ortam aydınlatmada kullanılabilir. Hareket, zaman ve günışığı sensörlü aydınlatmalar sayesinde aydınlatmanın gereksiz kullanımı ve uzun süreli yanması önlenmektedir (Şekil 3).

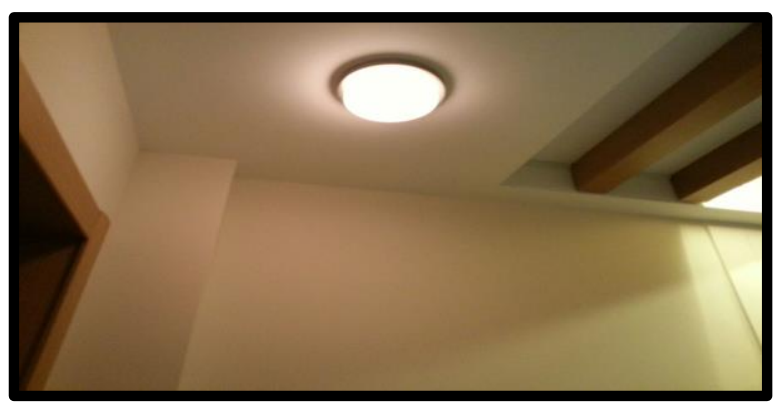

Şekil 3. Hareket, zaman ve günışığı sensörlü aydinlatmalar

\section{AKILLI BİNALARDA GÜVENLİK}

Günümüzde insanların konfordan beklentilerini karşılamanın yanı sıra güvenlik en önemli faktörlerin başında gelmektedir [12]. Bir binadaki güvenlik sistemleri, kontrol edilen bölgelerdeki detektörler, verilerin toplanarak değerlendirildiği kontrol üniteleri ve bu ünitelerin denetlendiği uyarı elemanlarından oluşmaktadır [13]. Güvenlik sistem otomasyonları bina sistemlerinin izlenmesine ek olarak acil durumlarda (yangın, deprem, hırsızlı) kullanıcı hatalarını ortadan kaldırarak en kısa sürede gerekli birimlere bildirilmesine ve gerekli sistemleri (yangın/hırsızlık alarmı, söndürme fıskiyeleri, acil çıkışların aydınlatılması gibi) çalıştırabilmektedir. Güvenlik sistemlerinin, yangın algılama, alarm, kamera, veri ve haberleşme sistemlerinin birbiriyle uyumlu bir şekilde çalışması tek merkezden kontrol edilmesi gerekmektedir (Şekil 4).

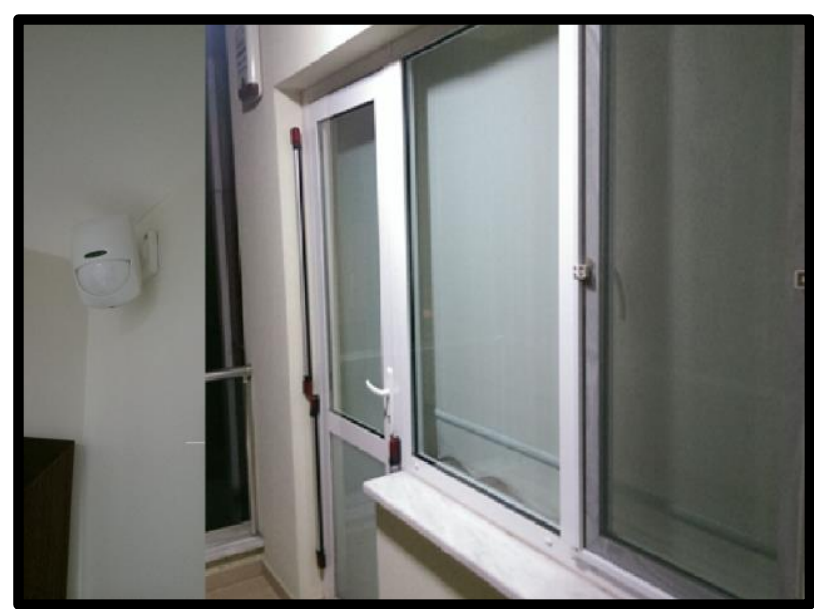

Şekil 4. Güvenlik sistem otomasyonu

Kameralar ve televizyon yardımı ile bina iç ve dışındaki tüm görüntüler izlenebilir. Hareket algılama durumunda ise sistem telefonlara mesaj gönderebilmektedir (Şekil 5). Ayrıca kontrol sistemleri kullanılarak evde yaşam izlenimi oluşturmak mümkündür.

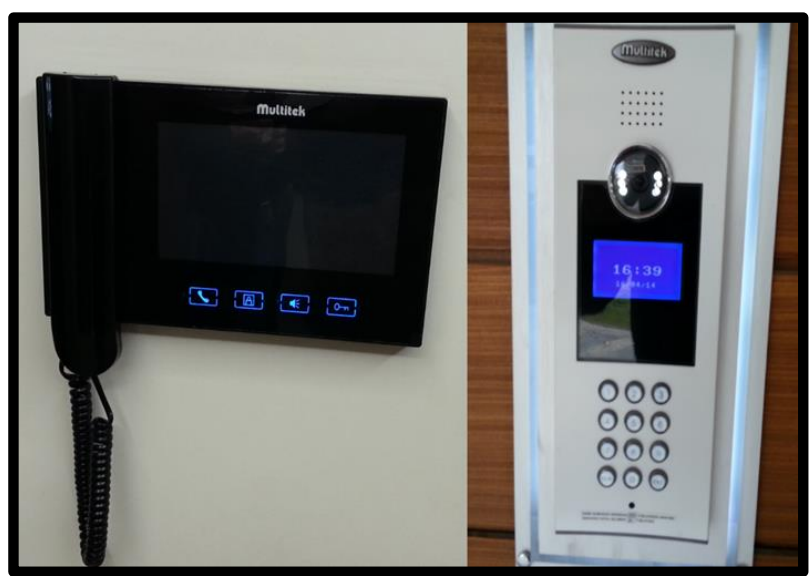

Şekil 5. Kameralar ve televizyon yardımı ile güvenlik otomasyonu 


\section{AKILLI BINNALARDA BİLGI TEKNOLOJILERİ UYGULAMASI}

Bu çalışma için Arduino IDE ve Appinventor yazılımları kullanılmıştır [14-15]. Appinventor programıyla, Android için yazılım geliştirilmiştir. Bluetooth haberleşmesi için kontrol tuşları eklenmiştir. Program aracılığıyla Android cihazlarda çalıştırılabilmesi için apk dosyası oluşturulup, telefona kurulmuştur. Arduino programı içinse, kullanılacak donanımlara bağlı olarak, dışarıdan gerekli kütüphaneler eklenmiştir. Arduino yazılımı ile her kütüphane yüklenmemektedir. Kullanılan donanımlara bağlı olarak sonradan eklenebilmektedir. Kullanılan her bir donanım için pin tanımlamaları yapılmıştır. Setup fonksiyonunda sistemi başlatmak için ayarlamalar yapılmıştır. Yazılan kodların daha iyi şekilde okunması ve kontrolü yapılabilmesi adına, her bir donanım için alt fonksiyon oluşturulmuştur (Şekil 5).

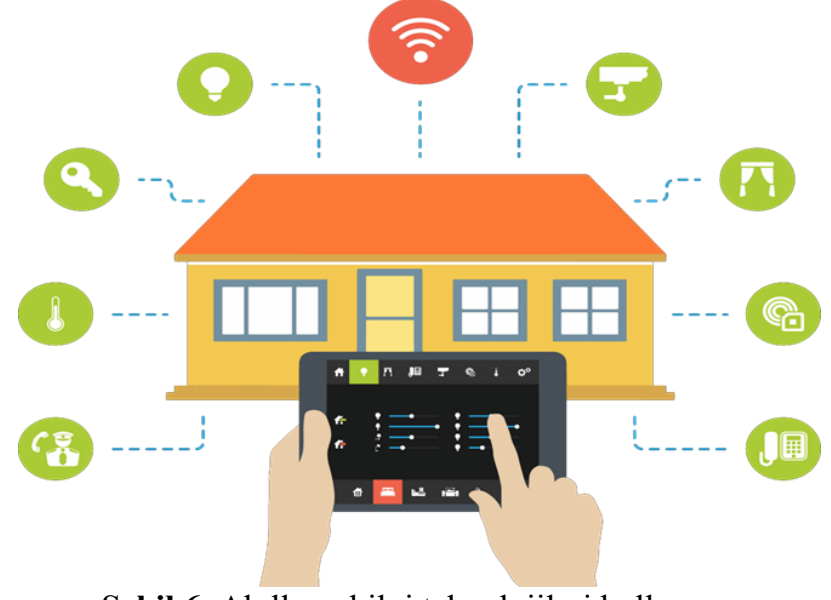

Şekil 6. Akıllı ev bilgi teknolojileri kullanımı

\section{TARTIŞMA VE SONUÇ}

Gelişen teknoloji, değişen yaşam tarzları, mekânlardan beklentilerin artması ve insanların ekonomik refahı ile birlikte inşaat sektöründeki ihtiyaç duyulan bina tipleri çok önemli değişim ve gelişmeye neden olmuştur. Gerek binaların yadsınamaz enerji kullanımındaki yeri gerekse kullanıcıların konfor ve refahını karşılamasından dolayı akıllı binalarda otomasyon sistem uygulamaları geliştirilmiştir.

Dijital çă̆ ile birlikte bilgisayar ve haberleşme alanlarındaki gelişmeler neticesinde akıllı bina tasarımları multidisipliner çalışmanın gerekliliğini ortaya çıkarmaktadır. Tükenmekte olan enerji kaynaklarını daha tasarruflu ve bilinçli kullanmak gelecek nesillere bırakabileceğimiz en önemli yatırımdır. Mimari parametreler, doğal havalandırma, güneş kontrolü, uygun kabuk seçimi, yalıtım, gelişen teknolojinin kullanımı ve mekatronik sistemlerin uyumuyla oluşturulan otomasyon sistemleri sürdürülebilir, çevreyle dost, kullanıcı konfor beklentilerini sağlayan ve yenilenebilir enerji kaynaklarını kullanabilen binaların önemini artırmıştır.

Akıllı binalar güvenlik ve konfor sağlamanın yanında zaman ve enerjiyi etkin kullanmakta ve otomasyon sistemleriyle kullanıcı hataları ortadan kaldırılarak sorumlulukları azaltılmaktadır. Akıllı binalarda kullanılan otomasyon sistemleri farklı kullanıcı ihtiyaçları için çeşitlendirilmelidir.

Güncel uygulamalar ile akıllı ev teknolojisi geliştirilmeye devam etmektedir. Mobil uygulamalara yönelik yeterli çalışma yoktur [16]. Bu çalışmada diğer çalışmalardan farklı olarak Android tabanlı uygulamalarında bu tür sistemlere katkı sağlayacağı gösterilmiştir. Bu çalışma ile birlikte Android tabanlı programlar, değișen ihtiyaçlara daha hızlı cevap verebilen modellere öncülük yapacaktır.

Sonuç olarak yapılan bu çalışmada, cep telefonu kullanarak istenilen anda evin sistemlerini açıp kapatılabilecek ya da kontrol edilebilecek bir sistem gerçekleştirilmiştir. Bu sistem sayesinde evdeki herhangi bir odanın 1şığını ve fanı sesli komut ile kapı aydınlatmasını telefondan tek tuşa basarak açabilir ve aynı zamanda bu devre elemanları çalışırken evin 1sı durumunu kontrol edebilir. Bundan sonraki çalışmalarda, bir yazılım geliştirilerek sistemin optimize edilebileceği düşünülmektedir.

\section{KAYNAKLAR}

[1] Mangan, S.D. (2006). Ak1llı Binalarda Alt Sistem Değerlendirmesi: İstanbul Örneği. İstanbul Teknik Üniversitesi Fen Bilimleri Enstitüsü, Yüksek Lisans Tezi.

[2] Yumurtacı, M. \& Keçebaş A. (2009). Akılllı Ev Teknolojileri Ve Otomasyon Sistemleri. 5. Uluslararas1 İleri Teknolojiler Sempozyumu. Karabük Üniversitesi, Karabük.

[3] Keskin, U. (2002). Modeling And Optimal Sizing Of A HVAC System Of Building. Boğaziçi Üniversitesi Fen Bilimleri Enstitüsü, Yüksek Lisans Tezi.

[4] Atabaş, İ., Arslan, M. \& Uzun, İ. (2007). Isıtma Sistemlerinin Otomasyonu Ve İnternet Üzerinden Kontrolü. Akademik Bilişim Kongresi. Dumlupınar Üniversitesi, Kütahya.

[5] Li, W., Yigitcanlar, T., Erol, I., \& Liu, A. (2021). Motivations, Barriers and Risks of Smart Home Adoption: from Systematic Literature Review to Conceptual Framework. Energy Research \& Social Science, 80, 102211.

[6] Sovacool, B. K., \& Del Rio, D. D. F. (2020). Smart Home Technologies in Europe: a Critical Review of Concepts, Benefits, Risks and Policies. Renewable and Sustainable Energy Reviews, 120, 109663.

[7] Yılmaz, Z. (2006). Akıllı Binalar Ve Yenilenebilir Enerji, Tesisat Mühendisliği Dergisi. Say1 91.

[8] De Paola, A., Ferraro, P., Re, G. L., Morana, M., \& Ortolani, M. (2019). A Fog-Based Hybrid İntelligent System for Energy Saving in Smart Buildings. Journal of Ambient Intelligence and Humanized Computing, 1-15. 
[9] Jabarullah, N. H., Shabbir, M. S., Abbas, M., Siddiqi, A. F., \& Berti, S. (2019). Using Random Inquiry Optimization Method for Provision of Heat and Cooling Demand in Hub Systems for Smart Buildings. Sustainable Cities and Society, 47, 101475.

[10] Kaiwen, C., Kumar, A., Xavier, N., \& Panda, S. K. (2016, November). An Intelligent Home Appliance Control-Based on WSN for Smart Buildings. In 2016 IEEE International Conference on Sustainable Energy Technologies (ICSET) (pp. 282-287). IEEE.

[11] Bayram, U. (2006). Akıllı Evler. Yüksek Lisans Tezi. Bilgisayar Anabilim Dalı, Fen Bilimleri Enstitüsü. Çanakkale Onsekiz Mart Üniversitesi, Çanakkale.

[12] Wendzel, S., Tonejc, J., Kaur, J., Kobekova, A., Song, H., Fink, G. A., \& Jeschke, S. (2017). Cyber Security of Smart Buildings. Wiley.

[13] Y1lmaz, C. \& Daldal, N.(2006). Pulse-DTMF Arama Tabanlı Bina Güvenlik Sistemi Tasarımı Ve Uygulaması. Pamukkale Üniversitesi Mühendislik Fakültesi, Mühendislik Bilimleri Dergisi. Cilt: 12, Sayı: 3. (s. 423428).

[14] https://www.arduino.cc/en/software (son erişim tarihi: 22.11.2021)

[15] https://www.arduino.cc/en/software (son erişim tarihi: 22.11.2021)

[16] Cafer, Ş., Okyar, Ö., Ateş, M. K., Kıran, M., Taşdemirci, Ç., \& Özkan, A. Mobil Uygulama Kontrollü Akıllı Hasta Odası Tasarımı. In International Marmara Sciences Congress (AUTUMN 2020) (p. 623). 